\title{
Manipulatives and Question Series for Elementary School Mathematics Teaching on Solid Geometry
}

\section{Isti Hidayah}

Dr., corresponding author, Mathematics Department, Universitas Negeri Semarang, Semarang, Indonesia, isti.hidayah@mail.unnes.ac.id

\section{Dwijanto}

Dr., Mathematics Department, Universitas Negeri Semarang, Semarang, Indonesia, dwijanto5@mail.unnes.ac.id

\section{Afit Istiandaru}

M.Pd., Mathematics Education Department, Universitas Ahmad Dahlan, Yogyakarta, Indonesia, afit.istiandaru@pmat.uad.ac.id
Some mathematics concepts, especially geometry, have not been understood well by students. The current curriculum in Indonesia strongly recommends the use of manipulatives in mathematics learning. However, the presence of manipulatives only cannot guarantee the students could construct their knowledge of concepts. This research aims to find out the effectiveness and the practicality of manipulatives use which is integrated with a series of written and oral questions in the solid geometry learning. It was an experiment using one group pretest-posttest design involving 32 students of fifth grade of elementary school and their teacher. The experiment resulted that there was an improvement of the students' understanding of solid geometry concepts by 0.54 in the intermediate category. Furthermore, the students' and the teacher's responses towards the learning were positive. The use of manipulatives and question series still demands the teacher ability to do connectivity and contrast when their students need. The conclusion of this research is that the use of manipulatives which is integrated with the series of written and oral questions is effective and practical to improve the students' concept understanding in the solid geometry learning. In the implementation, it is recommended for the teacher to prepare and to implement the learning appropriately and carefully.

Keywords: elementary school, manipulatives, mathematics concept, series of written and oral question, solid geometry

Citation: Hidayah, I., Dwijanto, \& Istiandaru, A. (2018). Manipulatives and Question Series for Elementary School Mathematics Teaching on Solid Geometry. International Journal of Instruction, 11(3), 649-662. https://doi.org/10.12973/iji.2018.11344a 


\section{INTRODUCTION}

The Indonesian curriculum introduces early concepts of geometry and measurement starts from the first grade of elementary school and then enriched in the next levels (MOEC, 2016).The first graders are introduced to the concept of plane figures and solid figures, such as cuboid, prism, cylinder, sphere, and cone, as the shapes appear in their daily life. In the second and third grade, the students learn mainly about plane figures. Further, the properties of plane and solid figures are discussed in the forth grade. In the fifth grade, the curriculum demands the students to be skilled in problem solving. However, many students experience difficulties in solving simple problems because of the lack understanding of the pre-requisite concepts (Hillman, 2003).

The condition becomes more problematic when their teachers do not correctly understand some geometry concepts, either. A survey towards a group of elementary school teachers towards some planar geometry problems described in Figure 1.

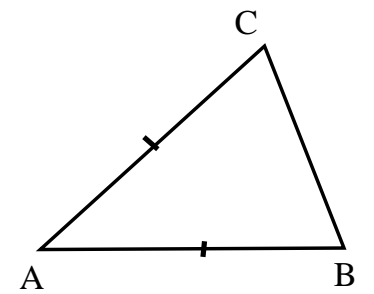

(a)

Problem 1: The figure above has ... shape and its base is ...

Figure 1

Problem examples on the survey to a group of elementary school teachers

Problem 1 presents a figure of isosceles triangle $A B C$ such that the edge $A B$ is in a horizontal position, then it was asked what the shape of the figure is and what the triangle's base is. Problem 2 presents a figure of the rectangle and its diagonals constitute four triangles, then it was asked if the adjacent triangles have the equal area. Among 29 teachers answering the first problem, there are $28 \%$ of them answered the first question correctly and failed to answer the second question, $10 \%$ of them answered the second question correctly but failed to answer the first question, $10 \%$ of them provided the wrong answer for both questions, $28 \%$ did not give any response, and $24 \%$ provided correct answer for both questions. While towards the second problem, it was only $3 \%$ provided the correct answer, $34 \%$ provided the wrong answer, and $62 \%$ did not answer.

The concepts of planar geometry are the pre-requisite to understanding the concepts and the principles of solid geometry. Students of elementary school are at the level of operational concrete thinking stage which means that they could think with the help of concrete material or manipulatives (Ojose, 2008). However, the presence of the manipulatives alone could not guarantee the meaningful learning happens unless they are used thoughtfully (Furner \& Worrell, 2017). It is the role of teachers who should be 
able to use the manipulatives to help the students understand the concepts well. In another hand, the use of manipulatives is challenged by the common belief of mathematics teachers. A case study by Moyer (2001) suggests that teachers usually use manipulatives just if they have extra time. This phenomenon is also commonly found in the Indonesian teachers' believe that the use of manipulatives in mathematics learning only wastes time and is not meaningful. It might because of the inappropriate use of manipulatives. Moreover, the presence of manipulatives is needed in solid geometry learning. The first Hiele stage of students' mental development in geometry also explains that students' visualization to recognize geometrical objects or concepts is based on prototype sample (Marchis, 2012; Nurhasanah et al., 2017).

The objects of mathematics are abstract, while the elementary students, in general, are still at the stage of concrete operational thinking (Ojose, 2008). Theories of learning by Piaget, Brunner, and Ausubel provide reinforcement to the importance of presenting concrete objects in mathematics learning such that the learning becomes meaningful, and therefore, the students could easily understand the concepts and are not easily forgotten (Ojose, 2008; Furner \& Worrell, 2017; Novak, 2002; Uttal et al., 1997, Cockett \& Kilgour, 2015; Larbi \& Mavis, 2016). Furthermore, the use of manipulatives in elementary school mathematics learning becomes necessary which makes teacher should consider providing the manipulatives (Hidayah \& Sugiarto, 2015). Learning mathematics will be meaningful if the learning is based on students' needs and mental condition. The learning will engage the emotions of students and thus the learning becomes meaningful (Webster-Stratton \& Reid, 2004).

An observation towards mathematics peer teaching activities in the scheme of teacher professional education and training of a group of elementary school teachers shows that their learning practice did not meet the characteristics of mathematics learning. Their learning practice tended to be a delivering information speech. There was no utilization of learning media such as manipulatives, students' worksheet, nor good questions. The learning did not give an opportunity for the students to be active or to find concepts or principles (Hidayah et al., 2013). Pujiastuti \& Mashuri (2015) states that students in elementary education still need manipulatives to help them understand the mathematics concepts. Teacher's skills to utilize manipulatives in mathematics learning supported by stimuli to trigger the students' activities will create a conducive learning atmosphere and make the students learn in an enjoyable way (Furner \& Worrell, 2017). However, some teachers are confused on how to use manipulatives in their mathematics learning as the curriculum recommends.

On the other hand, students' worksheet functions prominently to help the students in high-level mathematics thinking (Putra et al., 2017). The worksheet contains questions that break down the reasoning process into steps to guide students to provide reasoning and to build conceptual understanding. During the session when the teacher used the student worksheet, the students work collaboratively in groups containing three or four members. Teachers do not lecture or give answers but help the students to find their own answers by delivering questions series to guide them through a reasoning (Barniol \& Zavala, 2016). Guided questions help to some extent to help students who were unsure 
about their reasoning to get a correct answer and reasoning. However, in some cases, it is also possible that some students could not answer the questions correctly even with the guided questions provided (Garza \& Zavala, 2010).

The Indonesian curriculum requires each learning to be carried out using the scientific approach. This learning approach develops the students' skills to observe, to ask, to collect information, to associate in order to find a concept and to communicate in an integrated learning activity (MOEC, 2016). Various manipulatives as the innovation in mathematics learning have been developed to facilitate the students to find or to understand the mathematical concepts. They are produced by small industries that have been experienced in producing teaching aids in collaboration with us. Thus, the manipulatives quality can be maintained related to the mathematical concepts. The manipulatives are designed to support the implementation of the scientific approach.

The manipulatives prepared for this research are various models of planar figure: triangle, kinds of triangle, quadrilateral, kinds of quadrilateral, pentagon, hexagon, and circle. There are also various models of solid figures such as cuboid, cube, triangular prism, pentagonal prism, hexagonal prism, cylinder, quadrilateral pyramid, triangular pyramid, pentagonal pyramid, hexagonal pyramid, and cone which are used to find the concepts and properties of the solid figures. Besides, there are also manipulatives of solid figures' net. The manipulatives for the classical purpose are made following the standard size, and for solid figure manipulatives, the area of the same size are presented with the same color to help the students grasp the concept and properties of the figures.

This research raised prominent problems on whether the use of manipulatives and question series is effective to improve the students' conceptual understanding. Furthermore, we also figured out whether the students and the teacher respond positively towards the learning. This research aims to find out the effectiveness and the practicality of the manipulatives use integrated with a series of questions leading students to find concept by themselves in the solid geometry learning. The written stimulus was designed in a form of student worksheet equipped and student assignment containing exercises after students find the concept in group activities. The series of oral questions provided during the learning process to facilitate students' thinking activities. The effectiveness and the practicality are indicators of the high-quality learning devices (van den Akker, 1999).

\section{METHOD}

\section{Research Design}

The effectiveness of the manipulatives and question series was measured by looking at whether there is an improvement on the students' learning result before and after the learning, while the practicality was seen from the students' responses. This paper focuses on the testing of manipulative implementation in the solid figure material for elementary school. The testing was done using the one-group pretest-posttest experimental design (Koenig et al., 2012; Flasch et al., 2017). The design was chosen because the material in this research has been taught in the previous grade. 


\section{Participant}

This research involved the 5th-grade students of Sekolah Dasar Negeri Wetan 03 as its participants. It was an elementary school in Parakan District, Temanggung Regency, Central Java, has 32 students in the 5th grade. The subject was selected randomly among the elementary schools in Parakan which has implemented the 2013 Curriculum. The 2013 Curriculum is the current improved curriculum which the implementation is piloted gradually in Indonesia. In this research, all of the teachers involved have been trained on how to teach based on the 2013 Curriculum.

\section{Teaching Implementation Procedure}

In line with the research purpose, the learning devices were developed by research team involving the teacher of the selected testing classroom. The learning process was designed using a scientific approach referring to the Indonesian 2013 Curriculum. It was aided by manipulatives and a series of oral and written questions in the form of student worksheet. The learning scenario was developed referring to the manual of manipulative use in order to strengthen the learning objectives, including the explicit instruction which teacher needs to address to assist the students' thinking skill (Cope, 2015; Larbi \& Mavis,2016). In this research, the explicit instruction was then called question series, both orally addressed and written in the worksheet. It was prepared to facilitate the students to observe, to ask, to try, to associate (to find concepts or principles), and to communicate their findings. The learning was designed classical and within groups.

In order to accommodate the scope of material, the learning device was prepared for two meetings. The device was equipped with learning observation sheet to observe the conformity between the scenario and the implementation as well as to record the important findings. One of us took the role as the teacher while the teacher joined us as the observers. The first meeting started by administering pre-test, and a post-test was then administered at the end of the second meeting. Then, we collaboratively conducted reflection session towards the implementation of the learning as well as analyzing the tests result and the students' responses. The result of reflection was used to strengthen the finding analysis and discussion.

\section{Data Collection Instruments}

Based on the purpose of the testing, the effectiveness was shown by an increased result of pre-test and post-test of conceptual understanding. Meanwhile, the practicality was shown if the response of the students and the teacher towards learning are positive. The students' conceptual understanding towards solid figure was measured by a test, the students' response was measured by a questionnaire, while the teacher's response was measured by interview. We developed the test based on the test objective and specification in a form of short answer. The items were selected which usually the students usually make mistakes. It also applied to the development of the questionnaire used in this research. The teacher's ability to implement their learning based on the learning scenario was measured by using observation sheet which is developed referring to the learning process standard of the curriculum. This instrument is also as a control to find out the conformity between the learning implementation and the lesson plan. 


\section{Data Analysis Technique}

The collected data were analyzed statistically and narratively in order to provide a complete description of the results obtained. The data of pre-test, post-test and students' response towards the learning were tested normally distributed by using One-Sample Kolmogorov-Smirnov Test (Corder \& Foreman, 2009). The increase in the average scores of pre-test and post-test of solid geometry was calculated using the formula of normalized average gain is a comparison of the actual average gain to the maximum average gain. The actual average gain is the difference between the average score of the final test against the average score of the previous test. The formula of normalized gain which is also called the g-factor or Hake factor (Hake, 1999; Savinainen \& Scott, 2002) is:

$$
\langle g\rangle=\frac{\left\langle S_{\text {post }}\right\rangle-\left\langle S_{p r e}\right\rangle}{100-\left\langle S_{p r e}\right\rangle}
$$

The symbol $\langle g\rangle$ refers to the normalized average gain, the $\left\langle S_{\text {pre }}\right\rangle$ and the $\left\langle S_{\text {post }}\right\rangle$ respectively refer to the average score of pre-test and post-test. The categorization of gfactor is adopted and modified from Savinainen \& Scott (2002). It is categorized "high"

if $\langle g\rangle>0.7$, "intermediate" if $0.3<\langle g\rangle \leq 0.7$, and "low" if $\langle g\rangle \leq 0.3$. The descriptive analysis provides the explanation towards the findings of the conceptual understanding. It shows the percentage data of the students' correct answer between the pre-test and the post-test which has significant improvement and the students' response in a form of test result, questionnaire, and their engagement during the learning.

\section{FINDINGS}

The data of pre-test and post-test have been tested normally distributed by using oneSample Kolmogorov-Smirnov Test. The result suggests that the average score of pre-test is 33 with standard deviation 13.37 and the score of post-test is 69 with standard deviation 14.01. The g-factor is 0.54 which means there is an improvement of students' conceptual understanding in the intermediate category. Table 1 gives the descriptive percentage of the students who answered correctly before and after the treatment.

Table 1

Summary of Student Answered Correctly on the Pre-test and Post-test

\begin{tabular}{|c|c|c|c|}
\hline Number & Problems and Students' Answer & Pre-test $(\%)$ & Post-test (\%) \\
\hline \multirow[t]{2}{*}{$1-\mathrm{c}$} & Look at the cube model! & & \\
\hline & c. The shape of the edges is.....(line segment) & 0 & 94 \\
\hline \multirow[t]{2}{*}{ 4-c } & Look at the cylinder model! & & \\
\hline & c. The shape of the edges is .....(circle) & 3 & 72 \\
\hline \multirow[t]{2}{*}{$5-b$} & Look at the regular right triangular pyramid! & & \\
\hline & b. The shape of the lateral faces is ......(plane of isosceles triangle) & 2 & 67 \\
\hline \multirow[t]{3}{*}{$7-\mathrm{c}, \mathrm{d}$} & Look at the cone model! & & \\
\hline & c. The number of the edge(s) is ....(1) & 5 & 81 \\
\hline & $\mathrm{d}$. The shape of the edge(s) is ......(circle) & 0 & 86 \\
\hline
\end{tabular}




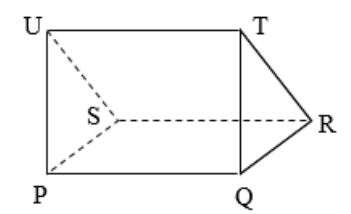

a. The shape of the figure above is .....(triangular prism)

b. The base is .....(plane of $\triangle \mathrm{PSU}$ or plane of $\triangle \mathrm{QRT})$

The data of students' response towards the learning using manipulatives, question series, and students' worksheet has been tested normally distributed by using One-Sample Kolmogorov-Smirnov Test. The average score of students' learning response is 3.42 from the maximum score 4 or 85.47 from the maximum score 100 . It shows that the students' response is positive. By using 95\% confidence, the average of students' response is at interval $83.34<\mu<87.60$. The description of the students' response towards learning is presented in Table 2.

Table 2

Percentage of the Students' Response towards the Learning Experience

\begin{tabular}{llc}
\hline Number & Aspect & Students' percentage \\
\hline 1 & Happy & 100 \\
2 & The teacher is interesting & 91 \\
3 & Classroom condition is enjoyable & 84 \\
4 & Get many new things to learn & 81 \\
5 & Same learning should be applied to the next material & 94 \\
6 & The material is easy to understand & 100 \\
7 & Learning using manipulative is enjoyable & 81 \\
8 & Students are active & 72 \\
\hline
\end{tabular}

The response of teacher towards the use of manipulatives and question series or written instructions to be done in groups (or in pairs) is positive. The learning could help the students to find the concept learned. The teacher's explanation and questions made the atmosphere of learning became more conducive, the students are passionate, happy, actively answer the questions, gives opinions, and actively come forward to present the solid figure concepts. The situations can be seen in Figure 2 and Figure 3.

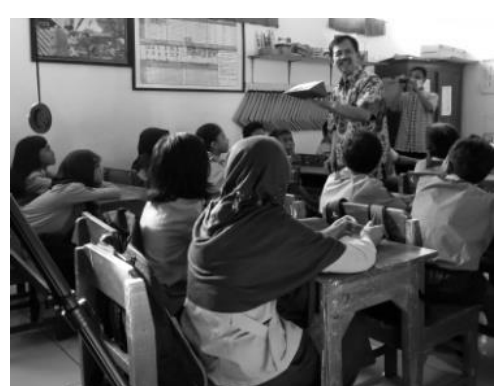

Figure 2

Teacher used the manipulatives of triangular prism and the oral questions 


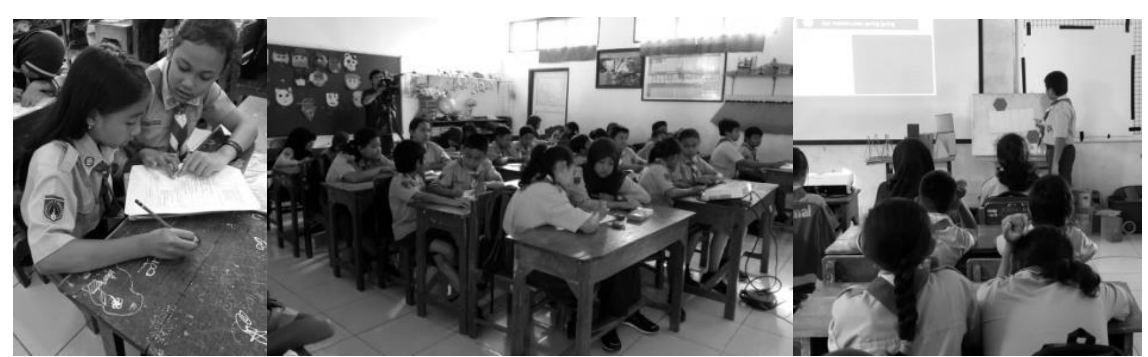

Figure 3

Students' activities

In this study, the researcher took the role as a teacher to implement the learning, while the real teacher took part as an observer. After observing the learning, the teacher admitted, "I have not yet used manipulatives in my class and the availability of the manipulatives in this school is still very limited". The teacher hopes that the learning device in this research can be owned and implemented at all schools so that future students can be more passionate about learning. The teacher was very impressed because students become excited, creative, and critical to find the concepts learned.

\section{DISCUSSION}

The findings of this research confirm that the use of manipulatives gives opportunities to the students to observe and to pay attention towards the teacher's statements and questions. The presence of manipulatives helps the students to think and to easily recall the concepts. We found that the students were happy to join this learning which utilized solid figure manipulatives, series of statements and questions, and worksheet. The students thought that they could understand the material through learning in group and demonstration in front of the class. The learning also improved the students' understanding towards solid geometry concepts to the "intermediate" criteria.

Based on the results of the analysis, it can be said that the use of manipulatives aided with student worksheets and a series of oral questions is effective and practical in mathematics learning, especially to understand the solid figure concepts of the fifthgrade elementary school students. When we examined the students' ability to answer each item of the problems, there are items which most of the students could not answer appropriately, namely the problem of the right triangular prism. We presented a picture of triangular prism model with one of its lateral faces in the horizontal position in Table 1 number 9a-b. There were only $34 \%$ students correctly answered that the figure is a triangular prism and only $19 \%$ students pointed its base correctly. Ironically, it happened when the teacher has used the proper triangular prism model and has demonstrated as mentioned in the procedure. This becomes an important note for the teacher that the use of manipulatives to make the concepts becoming more concrete should not stop this way but it should continue to relate them to the abstract concepts. The Brunner theory suggests that the internalization of concepts would really happen if a knowledge is learned following three stages, namely: the enactive, the iconic, and the symbolic stages (Sugiarto, 2012). A geometry learning should utilize the concrete 
model, followed by the presentation of the figure, and then ended by the explanation of its abstract concept. It is important for the teacher to prepare all the stages in order to get the optimal results. The teacher also has an important role in each learning stages. Shirvani (2015) explains that the teacher's knowledge affects the students' performance in mathematics. However, the content knowledge is not the only determining variable but also the other variables such as pedagogical knowledge, students and curriculum knowledge, and contextual knowledge. The use of manipulatives and the series of written and oral questions still demand the teacher ability to implement their learning appropriately and carefully.

A fragment description of the lesson plan and its implementation of the right triangular prism and its elements is presented below.

Teacher asks students to observe the model of the right triangular prism by position as shown in Figure 4.

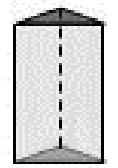

Figure 4

Triangular prism in the first position

Then, the teacher asks as follows.

1) What is the shape of the figure?(100\% answered correctly, triangular prism)

2) Why is it called triangular prism?(100\% answered correctly, because the base and the top have triangle shape)

3) Is the base a triangle or a plane of triangle?(some students answered correctly, plane of triangle)

4) Touch it with your hand, which is the base? (a student touch the correct base)

5) Teacher asks the other students, is it correct that the face touched is the base? $(100 \%$ answered correctly, yes )

6) Why is the face called base? (100\% wrongly answered, because the face is located at the base/lowest part).

7) Teacher asks all students to reconsider the first answer to the first question. What is the shape of the model?(triangular prism), why?(the base is plane of triangle). Please repeat again, why? (the base is a plane of triangle), repeat again why? (the base is a plane of triangle).

8) So, where is the base? (100\% correctly answered, the one which has plane of triangle shape)

9) Why is that called the base? (there is student answered, because the face has triangle face), can you repeat again? (100\% students answered correctly, because the face has a plane of triangle shape)

Later, the teacher did confirmation as follows.

10) So, why is the face called base? The answer is that because the face has a triangle shape and is not because of the position at the lowest part of the prism.

11) Look at Figure 4 again, how many lateral faces it has? (3), what is the shape of the lateral faces? (Most of the students answered, rectangle)The teacher repeated again, what is the shape of the faces (with higher tone)? (All students answered, plane of rectangle) 
12) The teacher repeated once more.Touch it which the base is. (Students touch the plane of triangle) why? (Because the face has a plane of triangle shape), what is the shape of the lateral faces? (Plane of rectangle)

Further, the teacher did contrast activities by changing the position of the model as shown in Figure 5, and then repeat what have been asked at previous activities.

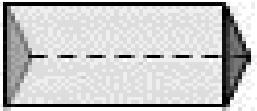

Figure 5

Triangular prism in the second position.

1) What is the shape of the figure?(some students answered pyramid, the others answered rectangular prism, the rest kept silent)

2) The teacher repeated the previous activity, holding the model of the prism as shown at Figure 4, and repeat to ask, the shape of the model at Figure 4 is ...(triangular prism), and then please look at Figure 5, what is the shape?

3) Some students answered again pyramid, the others answered rectangular prism, the rest kept silent. The next is teacher continued to do connectivity (connecting the existing knowledge with the knowledge which will be built) by asking students to observe the object they have already known, namely teacher himself.

4) The teacher asked, please look at me, who am I? (teacher), then the teacher lowered his bone forward and asked who he is (teacher), then he sat on a chair and asked the same, is it still the same teacher? (yes, students laughed), then teacher knelt, and asked again if he is still a teacher, or changed to be farmer or fishermen, (students laughed and answered, still a teacher)

5) The teacher soon took the prism model and put in various positions and then asked: What is the shape of figure 4 (triangular prism), What is the shape of figure 5 (the students laughed and answered triangular prism), teacher repeated again, what is the shape? (triangular prism). The teacher seemed satisfied and showed thumb up, and said, correct, correct, and correct.

6) The teacher held the model with the position of Figure 4 but placed it on his head and asked, what is the shape? (students laughed and answered, triangular prism), and then the model of the prism as shown in Figure 4 was placed below the armpit and he asked, what is the shape? (students laughed and answered, triangular prism). Later, the teacher asked students to observe the elements of a triangular prism. The teacher asked,: (a) What is the shape of Figure 4? (triangular prism), touch the base! (plane of triangle). (b)What is the shape of Figure 5? (triangular prism), touch the base!(most of the students touched the plane of rectangle), the teacher asked the other students to touch (the answer was the same).

7) The teacher did the connectivity again as follows: Who am I? (teacher). While touching his head, what is it? (head), the teacher took a lower position and asked while his hand still touching his head, what is it? (head), if I take a lower position, does my head change to be my feet? (no, still head)

8) The teacher soon asked the students to observe the model of the prism as shown in figure 4. What is it? (triangular prism), what is its base? (plane of triangle), is the plane of rectangle base of the prism? (no) so what is it? (lateral face).

In the above activities, a set of questions provided by the teacher serves as appropriate cues to help the students recall the knowledge stored in their long-term memory 
(Unsworth, 2016; Bhinnety, 2008). With a set of questions, the teacher tried to help the students to connect new information with the existing knowledge that has been owned by the students. In this case, the teacher has made connectivity to guide students to think and to find their own concepts learned. This cognitive guidance occurs when teachers guide the students to make connections between the new knowledge to the existing knowledge (Furner \& Worrell, 2017), and between the mathematics concept to the hands-on activities (Ojose, 2008), in order to encourage conceptual understanding.

The teacher did connectivity and contrast just if it is needed by the students. The teacher has tried to facilitate students in receiving, transforming, and transferring what they learned. The teacher has also done the presentation of the material from the enactive presentation through the iconic presentation to symbolic presentation. This learning is an implementation of Brunner learning theory (Hidayah et al., 2013). Students are expected to gain knowledge through invention. The purpose of this research is not only to acquire knowledge but to acquire knowledge in a way that could train the students' intellectual abilities, as well as to stimulate the students' curiosity and ability.

The presentation of contrast is used by the teacher to strengthen understanding of the concept that has been received in the previous learning process, as well as feedback for the teacher to find out whether the concept has been understood well by the students. If the concept is not well understood, then the contrast may generate conflict between the student and the problem arose. In this case, the student is expected to be challenged to find concepts or principles, as well as to improve students' reasoning. Thus, the concept which has been owned by students will be easily applied or transferred in the new situation. In geometry learning (solid figure), it also develops students' spatial abilities, particularly spatial orientation. According to Thurstone (as cited in Marchis, 2012), it is categorized as the ability to identify geometrical shapes within different positions.

Based on the principles of discovery learning, the teacher has designed and implemented treatment to facilitate the students to gain knowledge (concept) well. It is shown by the use of good questions during the learning process (Hidayah et al., 2013). Students' understanding of the concept of a triangular prism has been improved from pre-test to post-test, but it was not optimum when it is compared with the other concepts. From the results of observation and recording, some possible reasons of the not optimum percentage of the students who answered the item of triangular prism correctly have been found. The learning activities that have been performed show that students have demonstrated their understanding of the concept properly. However, according to the theory of meaningful learning, a concept which has been obtained by the student, if it is not meaningful for most students, it will not remain in the students' cognitive (Bhinnety, 2008). The possible cause is the inappropriate use of manipulatives by the teacher. The teacher should use manipulatives of a triangular prism with the color of the base and the top are different with the color of the lateral faces, while the manipulatives used by the teacher, in fact, was in one color of prism model.

Compared to the previous learning activities in the same meeting, the teacher utilized the correct manipulatives to make the students finding the concept of the cuboid and its elements as well as the cube and its elements. Meanwhile, at the time of the 
demonstration of a triangular prism, there is no student asked or expressed opinions regarding the visualization of the manipulatives used. At this moment, a disruption was probably happened in the students' mind to perform analogy between the concept which is currently being learned and the previous concepts. According to the Ausubel theory, it is explained that if the cognitive structure of students is not stable, doubtful, then the cognitive structure tends to inhibit the students' learning and retention (Dahar, 2011). Thus, it makes the concepts do not last long and are easy to forget.

Based on the discussion above, an important factor that must be considered and implemented for the optimum achievement of students' conceptual understanding is the role of the teacher. As explained in the appendix of the Regulation of Indonesian Ministry of Education and Culture number 22/2016 about the learning process standard, the teacher's duties are to design, to implement, to evaluate, and to perform follow up of learning. A lesson plan that has been perfectly developed does not guarantee optimal concept understanding of students when learning is not implemented as planned. It is also explained that one of the reasons led to unsatisfactory results of teaching geometry is because the teacher is not well prepared to teach. Teaching geometry is not only presenting the facts of geometry's indicated the solution of problems of geometry. It needs imagination, methodological skills, and most important, in-depth understanding of the ideas, methods, and constructions in school geometry (Bankov, 2013).

After the teacher mapped the concepts, the teacher needs to consider various learning theories to guide the implementation of the selected learning approach and method. The lesson plan should be written and operational. This also can be used by teachers to assess themselves during the learning process as a self-reflection to be followed-up.

\section{CONCLUSION}

The conclusions of this research are: (1) the use of manipulatives integrated into the solid geometry learning assisted with set of oral and written questions is effective and practical to improve the students' concept understanding, (2) the use of manipulatives that are integrated in the learning of solid figure assisted with set of oral and written questions will give students optimal understanding of the concept when teaching implementation carried out according to the written design that has been prepared.

\section{RECOMMENDATION}

In order to be effective and to meet the curriculum demand, when a teacher use manipulatives integrated with series of oral and written questions, it is recommended that the teacher prepare the lesson plan and implement it carefully.

\section{ACKNOWLEDGMENT}

We would like to thank the Directorate of Research and Community Service of the Indonesian Ministry of Research Technology and Higher Education who has provided a grant for this research through the competitive research scheme of Riset Andalan Perguruan Tinggi dan Industri (RAPID). We would like to also appreciate the principal of the school involved in this research for the access and support. 


\section{REFERENCES}

Bankov, K. (2013). Teaching of geometry in Bulgaria. European Journal of Science and Mathematics Education, 1/3, 158-164.

Barniol, P., \& Zavala, G. (2016). A tutorial worksheet to help students develop the ability to interpret the dot product as a projection. Eurasia Journal of Mathematics, Science and Technology Education, 12/9, 2387-2398.

Bhinnety, M. (2008). Struktur dan Proses Memori. Buletin Psikologi, 16/2, 74-88.

Cockett, A., \& Kilgour, P. W. (2015). Mathematical manipulatives: Creating an environment for understanding, efficiency, engagement, and enjoyment. TEACH COLLECTION of Christian Education, 1/1, 47-54.

Cope, L. (2015). Math manipulatives: Making the abstract tangible. Delta Journal of Education, 5/1, 10-18.

Corder, G. W., \& Foreman, D. I. (2009). Nonparametric Statistics: A Step-by-Step Approach. Hoboken: John Wiley \& Sons, Inc.

Dahar, R.W. (2011). Teori-Teori Belajar \& Pembelajaran. Surabaya: Erlangga.

Flasch, P., Taylor, D., Clauber, R. N., \& Robinson III, E. (2017). Examining students' perceived competence and comfort in an experiential play therapy counseling course: A single group pre-test post-test investigation. International Journal for the Scholarship of Teaching and Learning, 11/1, 1-6.

Furner, J. M., \& Worrell, N. L. (2017). The importance of using manipulatives in teaching math today. Transformations, 3/1, 1-25.

Garza, A., \& Zavala, G. (2010). Electric field concept: Effect of the context and the type of questions. AIP Conference Proceedings, 1289, 145-148.

Hake, R. R. (1999). Analysing change/gain scores. Indiana: Indiana University.

Hidayah, I., \& Sugiarto. (2015). Model of independent working group of teacher and its effectiveness towards the elementary school teacher's ability in conducting mathematics learning. Procedia-Social and Behavioral Sciences, 214, 43-50.

Hidayah, I., Sugiarto, \& Sutarto, H. (2013). Suplemen panduan guru dalam pengembangan pembelajaran tematik kompetensi dasar matematika kelas IV. Kreano, 4/2, 115-125.

Hillman, W. (2003). Learning how to learn: Problem based learning. Australian Journal of Teacher Education, 28/2, 1-10.

Koenig, K. P., Buckley-Reen, A., \& Garg, S. (2012). Efficacy to get ready to learn yoga program among children with autism spectrum disorders: A pretest-posttest control group design. The American Journal of Occupational Therapy, 66, 538-546.

Larbi, E., \& Mavis, O. (2016). The use of manipulatives in mathematics education. Journal of Education and Practice, 7/36, 53-61.

Marchis, I. (2012). Preservice primary school teachers' elementary geometry knowledge. Acta Didactica Napocensia, 5/2, 33-40.

MOEC. (2016). Regulation of the Indonesian ministry of education and culture number 22/2016 about the standard of process. Jakarta: Ministry of Education and Culture. 
MOEC. (2016). Regulation of the Indonesian ministry of education and culture number 24/2016 about core competence and basic competence. Jakarta: Ministry of Education and Culture.

Moyer, P. (2001). Are we having fun yet? How teachers use manipulatives to teach mathematics. Educational Studies in Mathematics, 47/2, 175-197.

Novak, J. D. (2002). Meaningful learning: The essential factor for conceptual change in limited or inappropriate propositional hierarchies leading to empowerment of learners. Science Education, 86/4, 548-571.

Nurhasanah, F., Kusumah, Y. S., \& Sabandar, J. (2017). Concept of triangle: Examples of mathematical abstraction in two different contexts. International Journal on Emerging Mathematics Education, 1/1, 53-70.

Ojose, B. (2008). Applying Piaget's theory of cognitive development to mathematics instruction. The Mathematics Educator, 18/1, 26-30.

Pujiastuti, E., \& Mashuri. (2015). Tracing of SMP mathematics teacher's skills in utilization of teaching aids through scientific approach. International Journal of Contemporary Applied Sciences, 2/11.

Putra, D., Herman, T., \& Sumarmo, U. (2017). Development of student worksheets to improve the ability of mathematical problem posing. International Journal on Emerging Mathematics Education, 1/1, 1-10.

Savinainen, A., \& Scott, P. (2002). The force to concept inventory: A tool for monitoring student learning. Physics Education, 37/1, 45-52.

Shirvani, H. (2015). Pre-service elementary teachers' mathematics content knowledge: Predictor of sixth graders' mathematics performance. International Journal of Instruction, $8 / 1$.

Sugiarto, S., Junaedi, I., \&Waluya, B. (2012). Pembelajaran Geometri Berbasis Enaktif, Ikonik, Simbolik untuk Menumbuhkan Kemampuan Berpikir Kreatif Peserta Didik Sekolah Dasar. Journal of Primary Education, 1/1.

Unsworth, N. (2016). Working memory capacity and recall from long-term memory: Examining the influences of encoding strategies, study time allocation, search efficiency, and monitoring abilities. Journal of Experimental Psychology: Learning, Memory, and Cognition, 42/1, 50-61.

Uttal, D. H., Scudder, K. V., \& DeLoache, J. S. (1997). Manipulatives as symbols: A new perspective on the use of concrete objects to teach mathematics. Journal of Applied Developmental Psychology, 18/1, 37-54.

van den Akker, J. (1999). Principles and methods of development research. In J. van den Akker, R. M. Branch, K. Gustafson, N. Nieveen, \& T. Plomp (Eds.), Design Approaches and Tools in Education and Training (1st edition). New York: Springer-Science+Business Media.

Webster-Stratton, C., \& Reid, M. J. (2004). Strengthening social and emotional competence in young children-The foundation for early school readiness and success. Infants \& Young Children, 17/2, 96-113. 